\title{
The Costs of Institutional Racism and its Ethical Implications for Healthcare
}

\author{
Amanuel Elias (1D) Yin Paradies
}

Received: 18 February 2020 / Accepted: 30 November 2020 / Published online: 2 January 2021

(C) Journal of Bioethical Inquiry Pty Ltd. 2021

\begin{abstract}
This paper discusses the ethical implications of racism and some of the various costs associated with racism occurring at the institutional level. We argue that, in many ways, the laws, social structures, and institutions in Western society have operated to perpetuate the continuation of historical legacies of racial inequities with or without the intention of individuals and groups in society. By merely maintaining existing structures, laws, and social norms, society can impose social, economic, and health costs on racial minorities that impinge on their well-being and human dignity. Based on a review of multidisciplinary research on racism, particularly focusing on healthcare, we demonstrate how institutional racism leads to social and economic inequalities in society. By positing institutional racism as the inherent cause of avoidable disparities in healthcare, this paper draws attention to the ethical significance of racism, which remains a relatively neglected issue in bioethics research.
\end{abstract}

Keywords Racism · Prejudice · Discrimination · Institutional racism

\footnotetext{
A. Elias $(\bowtie) \cdot$ Y. Paradies

Deakin University, 221 Burwood Hwy, Burwood, Victoria 3125, Australia

e-mail: amanuel.h@deakin.edu.au
}

Y. Paradies

e-mail: yin.paradies@deakin.edu.au

\section{Introduction}

Racism in healthcare poses a critical ethical problem (Danis, Wilson, and White 2016). Its prevalence can dissipate the trust that racial and ethnic minorities put in the healthcare system and undermine its ability to deliver equitable health services (Nelson 2002). On the other hand, a healthcare system that, in achieving the Rawlsian notion of "fair equality of opportunity," ensures equitable access to all segments of society, can generate more social trust (Green 2001). In a context of institutional barriers that preclude equitable access, healthcare services that adhere to a traditional individualistic ethos and ignore the cultural specificities of minority groups are likely to perpetuate existing disparities in health outcomes (Stone 2002). These barriers, which raise an important ethical challenge, have been conceptualized in the literature as institutional racism - a form of racism that represents actions, policies, and practices that result in ethnic/racial inequalities in life outcomes (Better 2008).

In the traditional redistributive notion of justice incorporated in Rawls' "ideal theory," racism as a systemic form of inequity is not explicitely addressed (Mills 2009). Although Rawls rejected racism as unjust, his conception of the "ideally just" society omits any consideration of racial oppression as one of the most important features of Western societies. Powers and Faden $(2006,8)$ provide an alternative theory in which oppressive structures such as racism and sexism are integrated as "multiclausal and multifaceted social structural barriers to achieving self-sufficiency." Institutionally, 
racism presents itself as a negation of justice, unfairly eroding the rights of ethnic/racial minorities with consequences of preventable disadvantages in health and well-being (Powers and Faden 2006). In this paper, we draw on multidisciplinary research on institutional racism to examine, with a particular focus on healthcare, the various social and economic costs it imposes on Australian society.

Institutional racism is widely documented outside healthcare, such as in law enforcement (Williams 2001; Newman, Dudley, and Steel 2008), and is regularly reported in media. For example, on July 25, 2016, an $\mathrm{ABC}$ Four Corners programme aired the abuse of Indigenous children in an Australian youth detention centre in Darwin. This shocked the nation and initiated a Royal Commission that concluded racism had a part to play in perpetrating such abuses on systemic scales (White and Gooda 2017). In Britain in 1993, when a young black student, Steven Lawrence was killed in a racially motivated attack, accusations of racist conduct were levelled against the metropolitan police. This led to an inquiry into police reaction and handling of the criminal investigation that followed the attack. The inquiry chaired by Sir William Macpherson concluded in the Macpherson Report that "institutional racism played a part in the flawed investigation by the police" (Bourne 2001, 7). In the United States, in the summer of 2014, police shot and killed two unarmed young black men in Ferguson (Missouri) and New York City, prompting widespread protests accusing the police of racial profiling. Unlike Australia and United Kingdom, there was no equivalent investigation in the United States concluding these incidents indicated underlying institutional racism, nor were there complete data on police shootings in general (Peeples 2019).

Nonetheless, the above three incidents have one thing in common, despite their occurrence in three different countries. They are not isolated incidents but are recurrent and reflective of systemic injustices that affect racial minorities in multiracial societies. For example, emerging U.S. data related to police shootings indicate a wide racial disparity, with black people twice as likely to be killed as their white counterparts (Peeples 2019; Washington Post 2019). It is true that the fatal police shootings graphically depict the tragic injustice of racism, yet they are also "everyday" symptomatic manifestations of the underlying institutional racism that pervades these societies. The issue of the systemic pervasiveness of racism has been a subject of considerable research over the last half century. The continued existence of practices, norms, and laws that unwittingly discriminate and disadvantage racial minorities makes the concept of institutional racism relevant today.

There is no doubt that explicit forms of institutional racism that emerged with the rise of European colonization, industrial capitalism, and the Atlantic slave trade continue to manifest in twenty-first-century Western societies. Centuries later, these legacies continue to be foundational to modern nation states, with racism lurking beneath the structures and institutions that privilege whiteness and disadvantage racial minorities (Fraser and Honneth 2003). Institutional racism as we know it today is not limited to explicit racial policies. While some openly discriminatory policies and practices - such as slavery, Jim Crow laws, Apartheid, and the White Australia Policy-have been abolished, the systems they pioneered remain. The prediction that racism would either be eliminated or driven out of the marketplace failed to materialize, and race in the twenty-first century remains a defining factor of one's place in society (Darity, Hamilton, and Stewart 2015; Better 2008). Our purpose, in this paper, is not to answer why racism continues to exist today. Rather, we suggest that understanding the historical basis of racism is important to grasping the institutional nature of the underlying racial inequities that deeply impact Western societies.

This paper focuses on the contemporary institutional aspect of racism, examining the systemic structures that perpetuate exclusion and racial inequity and assessing the prevalence and impact of institutional racism. Our purpose is to investigate whether and to what extent there are structural and systemic barriers, particularly in the Australian context, that continue to oppress racial and ethnic minorities. We begin in section two by conceptualizing racism as a system of social power, considering its manifestation across multiple domains, including law, political representation, education, employment, health, and business. Sections three and four present contexts and examples of institutional racism globally and in Australia. Section five discusses the costs of institutional racism, while section six contextualizes the ethical dimension of racism. We conclude in section seven.

\section{Conceptualizing Institutional Racism}

Racism transcends negative attitudes and prejudices, with prejudice representing only one aspect of racism 
(Henricks 2016). It can creep in every aspect of life and crystalize into pervasive institutional racism, persisting irrespective of the good or ill will of individuals and groups. Racism can occur irrespective of individual attitudes and beliefs, with significant effects on racial minorities. This aspect of racism occurs covertly and "persists through collective actions of even the well intentioned" (Henricks 2016, 1). Thus, racism, as such, is routinely perpetrated without intent through the structures of a society and is often embedded in institutions and social structures (Better 2008; Henricks 2016). Institutional racism involves practices, procedures, patterns, and policies that operate to privilege members of particular racial groups in every aspect of society (Better 2008; Paradies 2016). It is an exclusionary system where a group is denied access to rights and privileges conferred on some groups in the form of unearned advantage. Through the exclusionary "production, control and access to material, information and symbolic resources" in societies, institutional racism serves to widen power differential between racial groups (Paradies 2016).

\section{Institutional Racism}

The Macpherson Report defined institutional racism as "the collective failure of an organization to provide an appropriate and professional service to people because of their colour, culture or ethnic origin" (Macpherson 1999, section 6.34). Institutional racism has a structural dimension with various corporate bodies such as governments, organizations, corporations, or state institutions involved in the production of racial discrimination and inequities. Its institutional nature can also be reflected in formal and informal social institutionsnorms, laws, customs, policies, and practices - that systematically engage in the production of racial inequities. It is systemic in that it operates as if spontaneously, with or without individual agency. Changing individuals within an institution does not eliminate the underlying mechanisms that drive institutional behaviours and outcomes. As the Macpherson Report has argued, "if racist consequences accrue to institutional laws, customs or practices, the institution is racist whether or not the individuals maintaining those practices have racial intentions" (Macpherson 1999, section 6.30).

Carmichael and Hamilton (1967) were the first to coin the phrase "institutional racism" in reference to the systemic nature of racism prevailing in the United
States in the 1960s. According to Carmichael and Hamilton (1967), racism has both overt and covert manifestations. These interrelated forms of racism are exhibited interpersonally, with white individuals acting against black individuals, and collectively, with the white community acting against the black community. Carmichael and Hamilton (1967) respectively refer to these as individual and institutional racism. For them,

The first consists of overt acts by individuals, which cause death, injury or the violent destruction of property. ... [It] can frequently be observed in the process of commission. The second type is less overt, far more subtle, less identifiable in terms of specific individuals committing the acts. ... [It] originates in the operation of established and respected forces in the society, and thus receives far less public condemnation than the first type. (Carmichael and Hamilton, 1967, 20)

In Carmichael and Hamilton's conception, individual racial prejudice does serve as the motive behind institutional racism. Simultaneously, the institutional perspective sees racism as operating within broader social forces, since individuals are not "divorced from relationships, social acts, and socio-historical circumstances" (Henricks 2016, 1). Thus, both for analytical and anti-racism purposes, it is important to distinguish between the various forms of racism, understanding that the multiple forms and levels of racism do not occur separately. Whether manifesting through laws, norms, and policies, occurring through discrimination and unfair treatment by institutions, or exhibited through prejudicial attitudes and behaviours, racism is produced through the reciprocal interplay among all of these (Bourne 2001; Gee et al. 2019).

\section{Invisibility of Institutional Racism}

Institutional racism is not easy to detect, it is rarely visible to those that are privileged by it, and is sometimes undetectable to those impacted by it. One of the reasons for this is the fact that it does not require overt behaviour or attitudes of individuals or groups. Nor does it require the conscious prejudice of individuals and groups. For institutions to be racist, they need not plainly state racist policies. By merely following existing norms, practices, laws, and bureaucratic structures, they can perpetrate racism. For institutional racism to thrive, 
people need only be "colour blind," "meritocratic," ignore the reality of existing privilege and injustices, and simply let the systems and structures reproduce the status quo.

Healthcare is a typical example where institutional racism occurs, yet remains invisible. For example, research indicates that African American patients in the United States have long received suboptimal care relative to white patients when seeking medical treatment (Williams and Wyatt 2015). The situation persistseither through systemic neglect, victim blaming, or attempts to justify the disparities with factors other than racial bias (Noah 2002; Williams and Wyatt 2015; Feagin and Bennefield 2014). Another example of the invisibility of racism is the recent disparity in significantly higher mortality rate among African Americans during the novel coronavirus disease (COVID-19) pandemic. This disparate mortality depicts underlying health inequities that disproportionately impact upon African Americans. Despite this, for many the role of institutional racism as a social system remains hidden, explained away by factors other than racial injustice.

Institutional racism in healthcare thus persists by virtue of its invisibility at many levels: to patients, practitioners, and policymakers - to patients because they have no comparison for how other patients of a different race are treated; to clinicians who remain oblivious to their own implicit bias or justify and rationalize their explicit prejudices; and to administrators, who assume equitable treatment based on equality of opportunity without considerations of the growing conflicting evidence.

\section{Modelling Institutional Racism}

Institutional racism is multidimensional, occurring across various public domains including education, employment, residence, and healthcare, as well as law and justice. It can manifest at diverse levels of social and institutional space such as governance, policy implementation, service delivery, recruitment, employment, and reporting. In all of these, the effect is poor and adverse outcomes for racial minorities. Figure 1 conceptually maps the way institutional racism occurs and some of its adverse outcomes as it manifests across settings. The discourse of institutional racism focuses on the outcomes that result from the default practices, laws, and norms in society. While these outcomes, be they in the form of poverty, poor health, education, or death in custody, are constantly felt-often raising feelings of anger, powerlessness, and resentment among racial minorities - they can pass without notice among members of the racial majority, depending on their awareness of their privilege.

\section{Contexts of Institutional Racism}

In this section, we argue that racism is embedded in the social structures upon which Western society has been founded. Since the early twentieth century, scholars have understood that racism has a systemic dimension (Du Bois 1903 [2015]). The struggle for racial equality frustrated many as they understood that not only was anti-black animosity prevalent but the institutional structures in many societies were enabling racism by legitimizing racial inequality through segregation, discrimination, and racial violence. A century later, such inequities remain relevant and, in some cases (e.g., the case of minority incarceration), have worsened.

In his influential body of works, the American scholar W.E. Du Bois has documented the endemic nature of racism that cuts across the entire social, economic, and legal structures of U.S. society, with its deep effect on black peoples' structural disadvantage (Du Bois 1903 [2015]). Other scholars, including Myrdal, Becker, and Cox, showed the pervasiveness of racism and discrimination across domains (Becker 1957 [2010]; Cox 1948; Myrdal 1944 [1996] ). The Marxist scholar Oliver Cox specifically maintained that racism in the United States is an inherent system within the capitalist order and hence closely intertwined with classism (Cox 1948).

Since the articulation of institutional racism, which conceived racism as deeply embedded system of structural inequality that required institutional sanctions for its sustenance (Carmichael and Hamilton 1967), research on this topic has grown. There is now a large body of research documenting its prevalence in various contexts, including law enforcement (Bourne 2001), healthcare (Henry, Houston, and Mooney 2004), media (Kilty and Swank 1997), education (Bodkin-Andrews and Carlson 2014), and immigration policy (Hage 1998; Hing 2009). In this vein, many scholars have argued that racism is inherently embedded within social structures. Miller and Garran (2007) conceptualize institutional racism as a web, an interconnected system of institutional structures that combine to produce pervasive racial inequities in a society. This understanding sees 


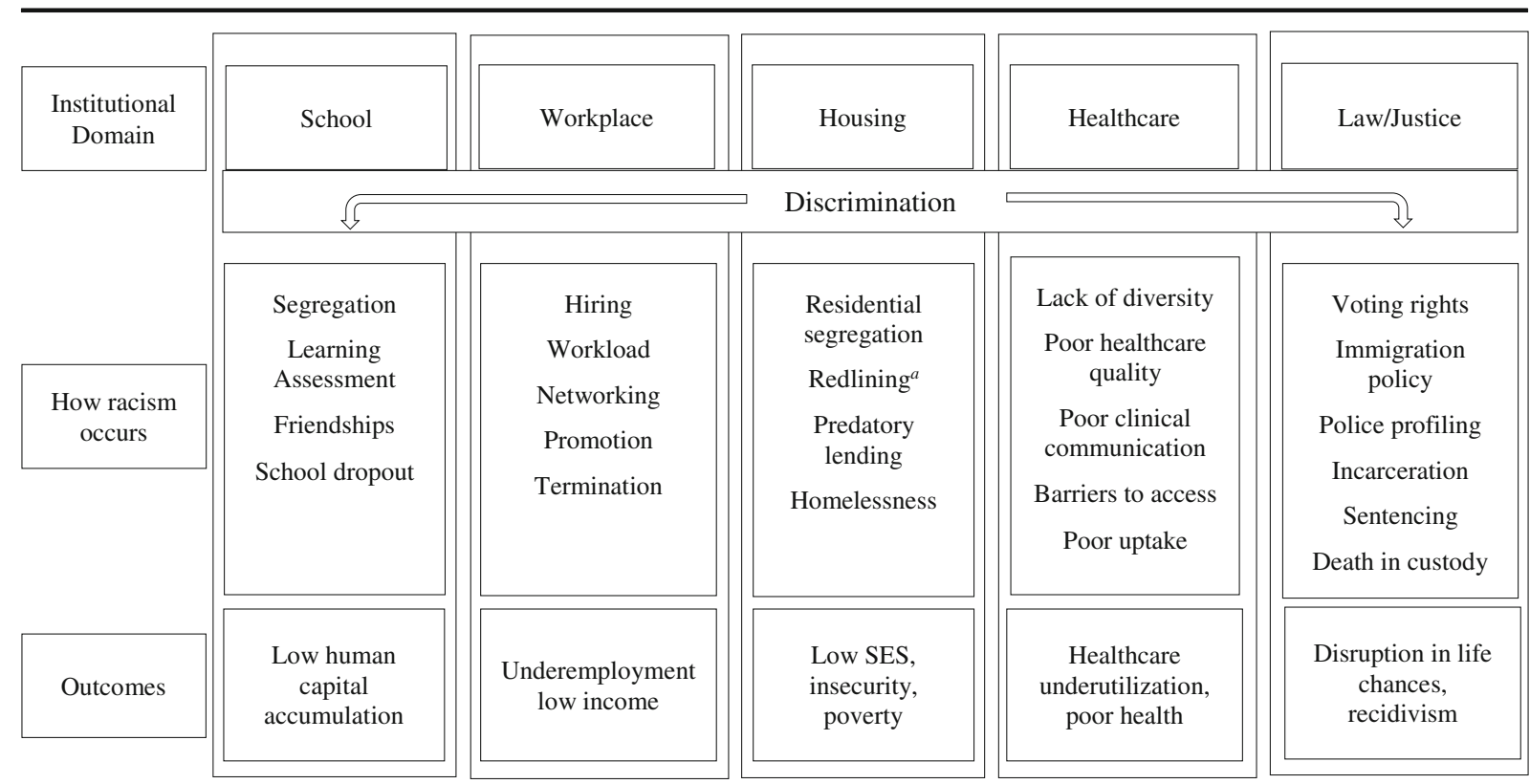

Figure 1 A model showing how institutional racism operates. Note. A model of institutional racism in modern societies. This diagram does not show historical institutional racism such as

racism as an inherently institutional phenomenon, in that its historical foundation has institutional roots. Whether expressed at the interpersonal level or internalized by targets of racism (Seet 2019), it persists only if it is institutionally enabled (Carmichael and Hamilton 1967). It is the power of institutions, be it in the form of discriminatory laws or structures of inequality and privilege that make racism far more devastating than mere personal prejudice. Historically, the institutions of slavery, Jim Crow, the Holocaust, Apartheid, and the White Australia Policy are among instances of institutional racism that inflicted substantial harm for racial minorities. In modern Western society, institutional racism may not be as overt as these historical racisms, despite its continued prevalence. Yet, its harmful impacts are nonetheless significant, with substantial inequities documented across countries (Feagin and Bennefield 2014; Fuller, Howard, and Cummings 2004; Henkel, Dovidio, and Gaertner 2006).

\section{Institutional Racism and Democracy}

Scholars have debated the ideological basis of racism, its connection with capitalism, and whether it is linked to class, caste, and/or other categories (Wilson 1996). Fraser and Honneth (2003) argue that racism has both social status and class dimensions. While neither slavery, the Holocaust, Apartheid, and the White Australia Policy. [a]Systematic denial of services in predominantly minority neighbourhoods.

dimension is a by-product of the other, they do interact to effect racial inequity. According to Fraser and Honneth $(2003,23)$, "[n]either can be redressed indirectly ... through remedies addressed exclusively to the other. Overcoming the injustices of racism, in sum, requires both redistribution and recognition."

Democracy does not guarantee racial equality. Although most Western societies uphold several democratic ideals, such as freedom, fairness, and equality, for much of their history they have had racist institutions. Democracy by the very nature of its institutions can lead to the perpetuation of racism. This was the case when the architects of federation enacted racial discrimination by passing the Immigration Restriction Act that established modern Australia as a haven for white people (i.e., the White Australia Policy) (Willard 1967).

This is consistent with what scholars have long argued: that the interests of powerful structures prohibit racial equality in a democratic system (Post 1991, 327):

The very aspiration to self-determination reinforces by empowering those existing inequalities by empowering those with the resources and competence to take advantage of democratic processes; it systematically handicaps socially 
marginalized groups who lack this easy and familiar access to the media of democratic deliberation.

Democracy by definition is majoritarian and as such can through the anonymity of the ballot box yield results that are contrary to racial equality. The election in several Western countries of politicians holding views that are considered racist reflects this inherent paradox. ${ }^{1}$ It is no wonder, therefore, that anti-discrimination activism and much of its gains (e.g., the Civil Rights legislations and the end of Apartheid) have come from beyond the representative democratic process. ${ }^{2}$ Indeed, one could argue that democracy does respond to popular pressure if such pressure reaches a critical mass. However, the system of representative democracy in itself is not immune to capture by systems of racial oppression.

\section{Denial of White Privilege}

Acknowledging that racism intentionally exists in many Western institutions to maintain white privilege is tantamount to admitting they are not essentially "just meritorious" societies (Better 2008; Littler 2018). Citizens in these societies are educated to think of their nations as countries based on certain ideals (Australia: fair go; Canada: fairness, inclusion, equality, diversity; United States: freedom, liberty, and the pursuit of happiness; U.K.: democracy, rule of law, respect, and tolerance). The notion of institutional racism unsettles the Western mind with a form of cognitive dissonance. Thus, generally unprepared to confront the unsettling fact, members of privileged groups find it "easier to blame the victims of inequality or lunatic fringe groups than to admit the reality of basic injustice that exists ...." (Better 2008, 13).

At the macro level, scholars emphasize how controlling and reforming existing institutions can be difficult, given they are products of a long history of prejudice. Old practices do die hard, and more so when they become part of a culture that privileges majority

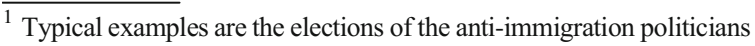
Nigel Farage in the U.K.; Marine Le Pen in France; the leader of an Austrian far right party, Norbert Hofer; the Islamophobe Dutch politician Geert Wilders; the anti-immigrant and Islamophobic politicians Pauline Hanson and Fraser Anning in Australia; the election of Donald Trump in the U.S.; and Jair Bolsonaro in Brazil.

${ }^{2}$ Stone (2002, abstract) suggests deliberative democracy as an alternative within healthcare settings to address ethnic disparities since fairness "requires proportional representation at all levels of decisions that affect healthcare."
}

groups and handicaps racial minorities. As Better (2008, 13) points out, "the dominant group in American society, Europeans, has justified its rule and exploitation of minority groups by building into its social institutions ideology as well as practices that supported this domination." Most institutions, including schools, local authorities, businesses, media organizations, congressional committees, and service providing agencies, "though often in the hands of enlightened persons, remain dominated by practices that produce racial inequities" (Better 2008, 13).

\section{Institutional Racism in the Australian Context}

Institutional racism in the Australian context is embedded in the white privilege that permeates the entire structure of Australian society. In this section, we unpack some of the historical factors that contribute to its perpetuation. Upon a contested historical premise that continental Australia was terra nullius (land of no one), the Commonwealth of Australia was established as an egalitarian democracy with progressive rights and privileges, exclusively for white British people (Bongiorno 2013). The colonial acquisition and expropriation of land belonging to Indigenous people started the long process of institutionalized racism, involving violence, dispossession, slavery, exploitation, and discrimination (Havemann 2005; Wolfe 2006). This concerted act was ideologically supported by the denial of "personhood, culture, and governance systems" of the Indigenous population, legitimizing "their exclusion from most benefits of modernisation" (Havemann 2005, 57). Today, institutional racism persists in the continuous denial of Indigenous rights and in Indigenous disadvantage (Chesterman and Galligan 1997; Head 2008). Indigenous disadvantage has been described as one of the wicked-i.e., persistent, complex, and intractableproblems in public policy in Australia (Head 2008). While this discourse has received some criticism for drawing on deficit discourse (Pyle 2018), it nonetheless reflects the effect of long-term discrimination and racial oppression.

Official institutional racism ended in Australia in the late 1960s, with the abolition of the laws that promulgated a White Australia Policy. Ever since, particularly in the late 1970s, the country has come to recognize itself as a multicultural society. The Racial Discrimination Act of 1975 affirms the equal rights of racial, ethnic, 
and religious minorities, prohibiting racial discrimination on the grounds of race, colour, ethnicity, religion, national origin, and so on. Despite this, Australian society remains largely dominated by the Anglo-European population with minorities less represented across power structures - politically and economically-although it prides itself as one of the most successful multicultural societies (Australian Human Rights Commission 2018). There is a widely held argument among researchers and practitioners that the socio-economic circumstances and political underrepresentation of minority groups point to ongoing systematic and structural racial inequality and injustice (Larkin 2013). Whether these are indicative of an underlying institutional racism, with race/ethnicity still determining one's place in Australian society, is a heavily debated issue across public policy and academic discourse (Bourke, Marrie, and Marrie 2018; Fuller, Howard, and Cummings 2004; Mellor 2003).

However, the evidence indicates that Indigenous Australians and many migrant communities experience unfair discrimination across several domains (Henry, Houston, and Mooney 2004; Fuller, Howard, and Cummings 2004). ${ }^{3}$ In addition, Australia has engaged in among the most inhumane treatment of asylum seekers in on-shore and offshore migrant detention centres of any country (McNeill 2003; Silove, Steel, and Mollica 2001). These kinds of discrimination and exclusion impact on the human rights of these groups (e.g., racial minorities and asylum seekers), with dire consequences for their health and well-being, as they tend to be disproportionately impacted by mental and physical illnesses (Newman, Dudley, and Steel 2008). Racial equality and justice are therefore yet to be realized within the Australian body politic.

Since the late 1970s, Australia has come to recognize itself as a multicultural country. While some see the selfidentification with the country's diverse cultural heritage as the country's progressive movement away from its racially exclusive history, the notion also generates critical, sometimes hostile denigration of the country's ethnocultural heterogeneity (Moran 2011). This is exemplified by the continued denial of Indigenous rights as symbolized in the ongoing debate of Indigenous constitutional recognition and in the socio-economic impoverishment of the Indigenous population. The reluctance to acquiesce with the heterocultural identity is

\footnotetext{
$\overline{3}$ These include the labour, housing, and consumer markets, healthcare, and criminal justice system.
}

also evidenced in the socio-economic exclusion and denigration of minorities from migrant backgrounds. Migrants from non-English speaking backgrounds (NESB), and particularly from certain communities (Africa, Asia, and the Middle East), tend to experience more social exclusion (Saunders, Naidoo, and Griffiths 2008; Taylor 2004). Racial equality and justice are therefore yet to be realized within the Australian body politic. Although Australia prides itself on being one of the most successful multicultural societies in the world, the society remains largely dominated by the AngloEuropean population, with minorities less represented across power structures - politically and economically.

\section{The Cost of Institutional Racism}

This section briefly discusses various costs society incurs as a result of institutional racism. While much of the impact falls on the targets of racism, there is wider implication to society either due to vicarious experiences of a group or due to the cumulative harm borne by society as a body politic. If society is considered as one body, the principle that "if one part of the body suffers, all the other parts suffer with it" applies. ${ }^{4}$

In one of our previous studies, we have estimated the economic costs that can be attributed to the prevalence of racism at the interpersonal and institutional levels (Elias and Paradies 2016). We particularly examined the health cost of racial discrimination, using burden of disease estimates to measure lost years due to mental health disability associated with experiences of racial discrimination. This is equivalent to the intangible cost associated with a particular health risk factor. Our findings showed that Australia may be losing around 3 per cent of its gross domestic product (GDP) annually due to racial minorities experiencing discrimination. Research in the United States found similar economic cost, with racial discrimination estimated to cost the United States to the tune of 3.8 per cent of GDP (Brimmer 1997). While Brimmer's and our estimations used human capital and standard health economic approaches respectively, in measuring the significant cost of racism we are aware that the impact of racism on human rights and dignity is far more consequential (Feagin and

\footnotetext{
${ }^{4}$ Both the Christian Bible and Muslim Quran state the notion that membership within a group implies that individual suffering is shared more widely.
} 
McKinney 2005). The latter raises important ethical issues that have been debated in the literature (Glasgow 2009).

An argument can be made that institutional racism may benefit some groups in society, despite society as a whole incurring costs overall. This benefit may come in the form of exclusive rights and privileges or in the form of social and economic opportunities. In their analyses of institutional racism in black incarceration in the United States, Henricks and Harvey demonstrate that entire industries in the city of Ferguson (Missouri) and Cook County (Illinois) - employees, businesses, contractors, and government agencies - stand to benefit from the perpetuation of the high rate of black incarceration in the country (Henricks and Harvey 2017; Henricks 2019). Self-interest motivates the police to arrest more, the employees secure their jobs as long as there are more inmates, business contractors increase their economic opportunities, and government agencies, including the prison facility, increase their budget depending on the number of inmates.

Hendricks (2019, abstract) identified three bureaucratic features of "mandatory financial sanctions" imposed on criminal convictions that help to sustain racial inequality:

One, these sanctions are represented in ways that abstract the conviction process from its highly racialized context. Two, these sanctions enable legal actors to enact a multilevel mode of decision making, combining compulsory and discretionary judgment, that entrenches racial bias within the broader legal organization of punishment. And three, these sanctions redistribute the operational costs of justice through earmarks onto those who are processed through the system (i.e., disproportionately people of colour). Altogether, these bureaucratic aspects paradoxically intensify racial stratification in ways that are seemingly nonracial.

What Henricks and others have shown is that racism occurring in law enforcement is perpetuated as a bureaucratic process, and this becomes a self-sustaining system. Its eradication becomes an issue of conflicting interests. Thus, the ultimate cost- the opportunity cost - of such institutional racism solidifies as the price associated with the "necessity to keep the system." Indeed, then the cost of dismantling institutional racism is likely to grow with the amount of resources invested to maintain the institutions that produced the racial disparities. The more racial inequities are left unaddressed the more intractable and socially costly they will become across generations.

Identifying the Costs of Institutional Racism

The costs of institutional racism extend to the human (health), economic, social, cultural, legal, and environmental spheres. In the legal context, we can see the significant mental health effect of racial profiling on racial minorities. Nations bear high social and economic cost associated with over-incarceration, recidivism, and death in custody. For example, Aboriginal deaths in custody in the period 1991-2016 fluctuated between 11 and 30 per cent of all deaths in custody (Gannoni and Bricknell 2019; Lyneham and Chan 2013). In the United States, studies have shown that the prison industry is affected by a moral hazard problem in that it has become dependent on the number of inmates (Henricks and Harvey 2017). Bhattacharyya, Gabriel, and Small (2016) make the observation that the prison-industrial complex, which is highly racialized, serves both the economic and ideological interests of the elitist state.

The social implications of institutional racism can also spill over to deeper societal structures in the form of family breakups, homelessness, social exclusion, and criminal involvement (Kerr et al. 2018). In the long term, such social problems can become culturally rooted and difficult to address (Wilson 2010). The current conditions of African Americans in the United States, Indigenous people in Australia, and Black people in South Africa are examples of this. Within such broad framing of institutional racism, we now discuss two examples of costs associated with institutional racism: economic and healthcare costs.

\section{Economic Costs of Institutional Racism}

By emphasizing "racism in effect" rather than "racism by intent," the concept of institutional racism analytically seeks to uncover established "actions, practices, and processes that reproduce variable yet stable racial hierarchies" (Henricks 2016, 2). These hierarchical patterns are observed in various socio-economic settings that disadvantage minority groups. In Australia, institutional racism has been shown to be pervasive in the labour market (Larkin 2013), education system (Bodkin- 
Andrews and Carlson 2014), and social services (Fuller, Howard, and Cummings 2004).

The economic cost of institutional racism is perhaps most visible in income inequality and wealth disparity. In the United States, this is reflected in acute residential segregation and the concentration of Black people in poor neighbourhoods, an intractable problem perpetuating black poverty (Lichter, Parisi, and Taquino 2012). In Australia, the racial income/wealth gap is acutely visible in the disparity between Indigenous people and white Australians (Larkin 2013; Fuller, Howard, and Cummings 2004). While the existing wealth gap in Australia largely reflects the historical colonial legacy of exclusion, current labour market conditions also explain the income disparity affecting Indigenous people (Larkin 2013). Larkin (2013) argues that ongoing colonialism and institutional racism have contributed to the chronic unemployment and underemployment that Indigenous people experience (Booth, Leigh, and Varganova 2012; Button and Walker 2019; Duncan, Mavisakalyan, and Tarverdi 2019).

Education is one of the contributing factors to the gap in income and employment outcomes between the Indigenous and non-Indigenous population. Studies report that racism as well as standard educational practices or policies in Australia (e.g., Eurocentric culture, English language as standard) place institutional barriers and adversely affect the Indigenous students (De Plevitz 2007; Moodie, Maxwell, and Rudolph 2019). This is reflected in achievement gaps as indicated in the 2018 Closing the Gap report which shows a persistent gap in attendance and retention rates, with worse outcome for remote communities (Australian Government 2019).

Another area where institutional racism has been a deeply rooted historical and contemporary phenomenon is the credit market. In a sweeping history of the U.S. banking system, Baradaran (2017) documents the systemic and pervasive nature of racial segregation and discrimination in the financial system that significantly restricted wealth accumulation among African Americans. According to Baradaran, "both active and latent racism have been the primary contributing factors to the persistence of racial inequality and the related disproportionate representation of blacks in poverty" (Venkatesan 2018). For Baradaran (2017), the U.S. credit market was ironically contrary to the free-market principle from the very beginning, with the big banks heavily relying on federal laws that protected their interests. In the end, the concentration of wealth racially disadvantaged black people who were systematically condemned to inner-city segregation and poverty.

Institutional Racism in Healthcare

Considerable research has reported evidence of implicit and explicit racist beliefs, emotions, or practices among healthcare providers (Maina et al. 2018; Paradies, Truong, and Priest 2014; Williams and Wyatt 2015). Within the healthcare system, racism was also associated with "lower levels of healthcare-related trust, satisfaction, and communication" (Ben et al. 2017, 1). The combined effect of poorer health services and healthcare underutilization is the deterioration of minority health outcomes, as is shown in Krieger (2020). This is clearly seen in Australia, in the poor health outcomes of $\mathrm{Ab}$ original and Torres Strait Islanders, as consistently reported in the Closing the Gap report. According to this report, social determinants of health and risk factors accounted for 53 per cent of the health disparity between Indigenous and non-Indigenous Australians while interpersonal and institutional racism and related factors accounted for the remaining 47 per cent (Bourke, Marrie, and Marrie 2018). Institutional racism places a heavy burden on the Indigenous people and is perpetuated by their systematic exclusion from the healthcare system. Many studies indicate that Indigenous patients have significantly low life expectancy, higher infant mortality rate, and higher prevalence of diseases compared to the rest of the population, and are less likely to receive appropriate treatment for a variety of illnesses (Bourke, Marrie, and Marrie 2018; Henry, Houston, and Mooney 2004). Added to these are inequities in healthcare funding, differences in treatment regimes, and cultural barriers to healthcare service use, which constitute evidence of institutional racism (Henry, Houston, and Mooney 2004).

Migrants and refugees are other groups that face structural and institutional barriers in the healthcare sector. Migrants from culturally and linguistically diverse (CALD) backgrounds in particular have often received disparate quality of care, with their access also limited by a range of factors (Johnstone and Kanitsaki 2008a). Research shows that access to health and healthcare are directly associated with an individual's race and ethnicity (Richardson and Norris 2010). While cultural and social barriers can prevent these groups from optimally accessing healthcare (Colucci et al. 2015), antipathy towards workplace diversity 
(Johnstone and Kanitsaki 2008b), systemic native ignorance (Mapedzahama et al. 2018), and race-related intersectional factors (Bastos, Harnois, and Paradies 2018) are also among the key institutional barriers in healthcare affecting migrants and refugees in Australia.

In addition to interpersonal and internalized forms of racism, the institutional barriers that Indigenous people and CALD migrants experience are not only key to their long-term health outcome, they also affect their overall well-being and life functioning (Fuller, Howard, and Cummings 2004; De Plevitz 2007). While Indigenous people have health outcomes that are equivalent to some of the poorest societies in the world, CALD migrants have poorer outcomes relative to white Australians (Bourke, Marrie, and Marrie 2018). These outcomes in a rich Western society with a healthcare system considered among the world's best represent an issue of significant ethical challenge, which we explore in the next section.

\section{The Ethics of Institutional Racism}

We have argued how institutional racism is socially costly because it imposes unfair and unnecessary inequities that harm the health and well-being of ethnic/ racial minorities. Yet, researchers have pointed out the relative neglect of racism as an ethical issue, particularly in healthcare ethics discourses (Johnstone and Kanitsaki 2010). In this section, we will explore how racism represents an important ethical issue. Johnstone and Kanitsaki (2010, abstract) argue that unless racism and racial disparities in healthcare receive due moral scrutiny and "unless racism is reframed and redressed as a pre-eminent ethical issue by health service providers," the preventable harms racism inflicts on ethnic/racial minorities "will remain difficult to identify, anticipate, prevent, manage, and remedy." A neglect of healthcare racism and subsequent perpetuation of systematic disadvantage trample both on Rawlsian notions of distributive justice (Rawls 2001) and Powers and Faden's (2006) conceptualization of justice based on human well-being.

As "unfair treatment" of human beings based on race, ethnicity, colour, and so on, it should be evident that racism is primarily a subject of ethics. Whether intentional or unwitting, a neglect of its existence as a systemic form of both injustice and privilege highlights and increases its harmful effects, as well as giving it legitimization and justification (Johnstone and Kanitsaki 2010; Noah 2002). Thus, an ethical discourse of racism, particularly as it relates to health service and healthcare, is an issue that needs urgent consideration to address the persistent systematic disadvantage and disparities racial and ethnic minorities invariably experience.

We have argued above that racism persists for the very reason that it serves the interests of racial majorities. We submit that racism is an ideology as well as an injustice (Boxill 2013). It entails attitudes, stereotypes, and beliefs in racial categories, and forms race relations with "hegemonic social function" (Shelby 2014, 66). Yet, what plausible ethical explanation do we have against racism? Why is it ethically objectionable? Many scholars argue that locating the ethical flaw of racism is easier when racism is conceived as an injustice rather than when it is understood as an ideology (Boxill 2013; Eidelson 2015; Thomsen 2017). In the literature, at least three reasons have been identified as core ethical failings of racism - disrespect, unfairness, and harm (Thomsen 2017).

The first explanation for the ethical flaw of racism lies in its inherent nature of being a "disrespect" towards target groups (Eidelson 2015; Glasgow 2009). Glasgow $(2009,84)$ argues that racism as a disrespect is located in the predisposition of a person or in "the mental state of the endorser." Such predisposition, whatever its extent or severity, can be conceived as the lack of respect for the worth and conditions of a particular group. To emphasize this argument, Glasgow $(2009,84)$ notes that "endorsing the statement 'All Arabs are terrorists' appears racist, but what's racist here is arguably not the proposition but the mental state of the endorser." Glasgow's conception of "racialized disrespect" notes that individuals and institutions can commit racist behaviours without harbouring racist attitudes (Levy 2017).

At the individual level, Blum (2002) locates the ethical objectionability of racism in two framingsracial antipathy and racial inferiorization. While bigotry, hatred, and hostility can be some expressions of racial antipathy, it is debatable whether such antipathy can be considered the fundamental or sole basis of racism (Shelby 2014). The other framing, inferiorizing racism, represents racism "expressed in various attitudes and behaviour - disrespect, contempt, derision, derogation, demeaning" Blum $(2002,10)$. This framing also includes the ideological aspect of racism. While Blum 
conceived it as distinct from racial antipathy, it nonetheless relies on psychological affect.

The problem with these propositions is that while explaining - to some extent - individual racism, they do not adequately address in what sense structural and institutional racisms can be understood as disrespect. People can be considered racist for beliefs and behaviours passing as racialized disrespect, yet racialized disrespect is not a necessary condition for institutional racism. In fact, the structural and institutional aspects of racism have been understood as racism without racists (Bonilla-Silva 2006; Massey, Scott, and Dornbusch 1975).

The second explanation regarding the ethical flaw of racism lies on its unfairness. Racism - interpersonal or institutional - is ethically indefensible as it fundamentally tramples on justice, equality, and human dignity by imposing bias and inequity based on unfair socially constructed human difference. Rawls (2001) in his conceptualization of justice as fairness argues that discrimination on the grounds of race and gender is a fundamental flaw in a well-ordered liberal society. Half a century before Rawls, scholars have considered institutionally sanctioned racism an existential paradox and dilemma in Western society (Du Bois 1903 [2015]; Myrdal 1944 [1996]). From an ethical perspective, we propose that the paradox of the continued persistence of institutional racism in otherwise egalitarian societies can be conceived as the lack of "other-regarding" virtue, which is a kind of "indifference." Indeed, the Rawlsian conception of justice does not formally incorporate regard for others within the framework of the "veil of ignorance" although it denotes some element of selfothering. Nonetheless, we can still argue that in a sense, "a proper moral perspective is somewhat otherregarding and impartial ..." (Hill Jr 1989, 765). Rawls himself has recognized later that the non-incorporation of racial discrimination in his Theory of Justice was an important omission (Rawls 2001, 66). Thus, the concept of "other regard" can be seen in his proposition that distinctions (discrimination) can only be justified in the specific case where it is applied to remedy historical inequity.

Indeed, racism as a historical and contemporary system of inequity is an embodiment of injustice. In our view, it can be conceived as the notion of not giving due attention to the unfair disadvantage of certain groups and to the unearned advantages of other groups (white privilege) (Nixon 2019). Individually, this can be conceptualized as disregard or disinterest in the condition of the racial other. At the institutional level, this would involve a collective failure to consider the conditions of racial minorities. In this sense, institutional racism becomes inherently contradictory to the ethical notion of "other regarding" morality.

Conceptualizing racism as a lack of regard for racial minorities enables us to capture the range of ways racism has been conceived in the literature (such as modern racism, aversive racism, ambivalent racism, and subtle racism). This conceptualization can also incorporate the notion of "disrespect" proposed by Glasgow (2009). Disrespect can be considered a specific aspect of disregard for others. The difference between these two lies in that "other-regard" need not be located in a person's mental predisposition while disrespect essentially does. The former can exist even when all members of society maintained some kind of respect for racial minorities. Institutional racism is a case in point. It can thrive even under the condition where all members of society maintain respect for black people, that is, racism without racists. This is the case because one can still be respectful towards Blacks while being indifferent to their conditions.

A third explanation pointing to the ethical flaw of racism is that it harms the target groups. A substantial body of evidence has been produced across countries, indicating the harmful effects of racism (Paradies et al. 2015). The health costs related to racism we discussed in this chapter provides a clear example of such an evidence. Racism harms those who experience it, and thus as such can arguably qualify as ethically objectionable behaviour or phenomena, irrespective of underlying beliefs, attitudes, or antipathy.

\section{Conclusion}

Institutional racism reflects a collective injustice in society that harms racial minorities. More than fifty years after the first coining of the concept, research shows that it is far from being eliminated in many societies. This paper discussed how institutional racism, in its less overt form, continues to affect racial minorities through structures that unfairly perpetrate injustices that are, to a large extent, the legacies of historical racist structures and systems. We argued that across domains including education, housing, workplace, healthcare, and criminal justice racism tends to be institutionally enabled to 
unwittingly perpetuate inequitable outcomes for racial minorities.

In an ethnoculturally heterogeneous society, institutional racism can be socially and economically costly, as minorities experience systematic exclusion and discrimination. Furthermore, in societies that consider democracy and freedom as their central tenets, institutional racism raises fundamental ethical questions. While democracy is based on egalitarian principles and equal representation, racism - and discrimination-limit the ability of racial minorities to fully participate in social and political life. This was one of the main reasons for the Civil Rights movements of the 1960s (Carmichael and Hamilton 1967).

Three fundamental reasons - disrespect, unfairness and harm - have been proposed as the core ethical flaws of racism. Within the unfairness paradigm, the ethical question of racism broadly and institutional racism specifically can be seen in the notion of racism as a disregard for racial minorities. This locates the fundamental ethical flaw of racism in the failure of individual citizens and society to consider the conditions of racial minorities. From this perspective, society would be shirking its obligation towards its minority citizens. Our proposition of racism an ethical dilemma is corroborated by the racism scholarship that dates back to the works of $\mathrm{Du}$ Bois (1903 [2015]), Myrdal (1944 [1996]), and others.

\section{References}

Australian Government. 2019. Closing the Gap Report 2019. Canberra.

Australian Human Rights Commission. 2018. Leading for change: A blueprint for cultural diversity and inclusive leadership revisited. Sydney: Australian Human Rights Commission.

Baradaran, M. 2017. The color of money: Black banks and the racial wealth gap. Cambridge: Belknap.

Bastos, J.L., C.E. Harnois, and Y.C. Paradies. 2018. Health care barriers, racism, and intersectionality in Australia. Social Science and Medicine 199: 209-218.

Becker, G. S. 1957 [2010]. The economics of discrimination. Chicago: University of Chicago press.

Ben, J., D. Cormack, R. Harris, and Y. Paradies. 2017. Racism and health service utilisation: A systematic review and metaanalysis. PLOS One 12(12): e0189900.

Better, S. 2008. Institutional racism: A primer on theory and strategies for social change. Lanham: Rowman and Littlefield Publishers.

Bhattacharyya, G., J. Gabriel, and S. Small. 2016. Race and power: Global racism in the twenty first century. London: Routledge.
Blum, L. 2002. "I'm not a racist, but ...”: The moral quandary of race. Ithaca, NY: Cornell University Press.

Bodkin-Andrews, G., and B. Carlson. 2014. The legacy of racism and Indigenous Australian identity within education. Race Ethnicity and Education 19(4): 784-807.

Bongiorno, F. 2013. A working man's paradise? In Glorious days: Australia 1913, edited by S. Macintyre, P. Stanley, and T. Griffiths, 109-119. Canberra: National Museum of Australia Press.

Bonilla-Silva, E. 2006. Racism without racists: Color-blind racism and the persistence of racial inequality in the United States. Lanham, MD: Rowman and Littlefield Publishers.

Booth, A.L., A. Leigh, and E. Varganova. 2012. Does ethnic discrimination vary across minority groups? Evidence from a field experiment. Oxford Bulletin of Economics and Statistics 74(4): 547-573.

Bourke, C.J., H. Marrie, and A. Marrie. 2018. Transforming institutional racism at an Australian hospital. Australian Health Review 43: 611-618.

Bourne, J. 2001. The life and times of institutional racism. Race and Class 43(2): 7-22.

Boxill, B.R. 2013. Racism. In The international encyclopedia of ethics, edited by H. LaFollette. Blackwell Publishing Ltd.

Brimmer, A. 1997. The economic cost of discrimination against black Americans. In A different vision: Race and public policy, edited by T. Bostorn, 1-16. London: Routledge.

Button, P., and B. Walker. 2019. Employment discrimination against Indigenous peoples in the United States: Evidence from a field experiment. IZA Discussion Papers, No. 12131, Institute of Labor Economics (IZA), Bonn.

Carmichael, S., and C.V. Hamilton. 1967. Black power: The politics of liberation in America. Harmondsworth: Penguin Books Ltd.

Chesterman, J., and B. Galligan. 1997. Citizens without rights: Aborigines and Australian citizenship. Cambridge: Cambridge University Press.

Colucci, E., H. Minas, J. Szwarc, C. Guerra, and G. Paxton. 2015. In or out? Barriers and facilitators to refugee-background young people accessing mental health services. Transcultural Psychiatry 52(6): 766-790.

Cox, O. 1948. Caste, class, and race: A study in social dynamics. Garden City: Doubleday and Company.

Danis, M., Y. Wilson, and A. White. 2016. Bioethicists can and should contribute to addressing racism. The American Journal of Bioethics 16(4): 3-12.

Darity, W.A., D. Hamilton, and J.B. Stewart. 2015. A tour de force in understanding intergroup inequality: An introduction to stratification economics. The Review of Black Political Economy 42(1-2): 1-6.

De Plevitz, L. 2007. Systemic racism: The hidden barrier to educational success for Indigenous school students. Australian Journal of Education 51(1): 54-71.

Du Bois, W. 1903 [2015]. The souls of black folk. New Haven: Yale University Press.

Duncan, A., A. Mavisakalyan, and Y. Tarverdi, 2019. Selfassessed vs. statistical evidence of racial discrimination: The case of indigenous Australians. Applied Economics Letters 51(12): 1232-1247.

Eidelson, B. 2015. Discrimination and disrespect. Oxford: Oxford University Press. 
Elias, A., and Y. Paradies. 2016. Estimating the mental health costs of racial discrimination. BMC Public Health 16(1): 1205.

Feagin, J.R., and K.D. McKinney. 2005. The many costs of racism. Lanham: Rowman and Littlefield Publishers.

Feagin, J., and Z. Bennefield. 2014. Systemic racism and US health care. Social Science and Medicine 103: 7-14.

Fraser, N., and A. Honneth. 2003. Redistribution or recognition? A political-philosophical exchange. London: Verso.

Fuller, D., M. Howard, and E. Cummings. 2004. The impact of institutional racism upon indigenous economic and human development in Australia. Development in Practice 14(4): 559-568.

Gannoni, A., and S. Bricknell. 2019. Indigenous deaths in custody: 25 years since the Royal Commission into Aboriginal Deaths in Custody. Statistical Bulletin 17. Canberra: Australian Institute of Criminology.

Gee, G., A. Hing, S. Mohammed, D. Tabor, and D. Williams. 2019. Racism and the life course: Taking time seriously. American Journal of Public Health 109(S1): S43-S47.

Glasgow, J. 2009. Racism as disrespect. Ethics 120(1): 64-93.

Green, R.M. 2001. Access to healthcare: Going beyond fair equality of opportunity. American Journal of Bioethics 1(2): 2223.

Hage, G. 1998. White nation: Fantasies of white supremacy in a multicultural society. Annandale: Pluto Press.

Havemann, P. 2005. Denial, modernity and exclusion: Indigenous placelessness in Australia. Macquarie Law Journal 5: 57-80.

Head, B. 2008. Wicked problems in public policy. Public Policy 3(2): 101-118.

Henkel, K.E., J.F. Dovidio, and S.L. Gaertner. 2006. Institutional discrimination, individual racism, and Hurricane Katrina. Analyses of Social Issues and Public Policy 6(1): 99-124.

Henricks, K. 2016. Racism, structural and institutional. In The Wiley Blackwell encyclopedia of race, ethnicity, and nationalism, 1st ed., edited by J. Stone, R. M. Denis, P. Rizova, A. D. Smith, and X. Hou, 1-8. Chichester: John Wiley and Sons.

. 2019. Power to the paperwork? Mandatory financial sanctions and the bureaucratic means to racially unequal ends. American Behavioral Scientist. https://doi. org/10.1177/0002764219859620.

Henricks, K., and D. Harvey. 2017. Not one but many: Monetary punishment and the Fergusons of America. Sociological Forum 32: 930-951.

Henry, B.R., S. Houston, and G.H. Mooney. 2004. Institutional racism in Australian healthcare: A plea for decency. Medical Journal of Australia 180(10): 517-520.

Hill Jr, T.E. 1989. Kantian constructivism in ethics. Ethics 99(4): $752-770$.

Hing, B.O. 2009. Institutional racism, ICE raids, and immigration reform. University of San Francisco Law Review 44: 307.

Johnstone, M.J., and O. Kanitsaki. 2008a. The problem of failing to provide culturally and linguistically appropriate healthcare. In Analysing Australian health policy: A problem orientated approach, edited by S. Barraclough and $\mathrm{H}$. Gardner, 176-187. Sydney: Elsevier.

2008b. The politics of resistance to workplace cultural diversity education for health service providers: An Australian study. Race Ethnicity and Education 11(2):133154.
2010. The neglect of racism as an ethical issue in health care. Journal of Immigrant and Minority Health 12(4):489495.

Kerr, J., P. Schafer, A. Perry, J. Orkin, M. Vance, and P. O'Campo. 2018. The impact of racial discrimination on African American fathers' intimate relationships. Race and Social Problems 10(2): 134-144.

Kilty, K.M., and E. Swank. 1997. Institutional racism and media representations: Depictions of violent criminals and welfare recipients. Sociological Imagination 34(2-3): 105-128.

Krieger, N. 2020. Measures of racism, sexism, heterosexism, and gender binarism for health equity research: From structural injustice to embodied harm: An ecosocial analysis. Annual Review of Public Health 41(4): 1-26.

Larkin, S.R. 2013. Race matters: Indigenous employment in the Australian public service. $\mathrm{PhD}$ thesis, Queensland University of Technology.

Levy, N. 2017. Am I a racist? Implicit bias and the ascription of racism. The Philosophical Quarterly 67(268): 534-551.

Lichter, D.T., D. Parisi, and M.C. Taquino. 2012. The geography of exclusion: Race, segregation, and concentrated poverty. Social Problems 59(3): 364-388.

Littler, J. 2018. Against meritocracy: Culture, power and myths of mobility. London and New York: Routledge.

Lyneham, M., and A. Chan. 2013. Deaths in custody in Australia to 30 June 2011. AIC Reports. Canberra: Australian Institute of Criminology.

Macpherson, W. 1999. The Stephen Lawrence Inquiry: Report of an inquiry by Sir William Macpherson of Cluny. London: HMSO.

Maina, I.W., T.D. Belton, S. Ginzberg, A. Singh, and T.J. Johnson. 2018. A decade of studying implicit racial/ethnic bias in healthcare providers using the implicit association test. Social Science and Medicine 199: 219-229.

Mapedzahama, V., T. Rudge, S. West, and K. Kwansah-Aidoo. 2018. Making and maintaining racialised ignorance in Australian nursing workplaces: The case of black African migrant nurses. Australasian Review of African Studies 39(2): 48.

Massey, G.C., M.V. Scott, and S.M. Dornbusch. 1975. Racism without racists: Institutional racism in urban schools. The Black Scholar 7(3): 10-19.

McNeill, P.M. 2003. Public health ethics: Asylum seekers and the case for political action. Bioethics 17(5-6): 487-503.

Mellor, D. 2003. Contemporary racism in Australia: The experiences of Aborigines. Personality and Social Psychology Bulletin 29(4): 474-486.

Miller, J., and A.M. Garran. 2007. The web of institutional racism. Smith College Studies in Social Work 77(1): 33-67.

Mills, C.W. 2009. Rawls on race/race in Rawls. The Southern Journal of Philosophy 47(S1): 161-184.

Moodie, N., J. Maxwell, and S. Rudolph. 2019. The impact of racism on the schooling experiences of Aboriginal and Torres Strait Islander students: A systematic review. The Australian Educational Researcher 46(2): 273-295.

Moran, A. 2011. Multiculturalism as nation-building in Australia: Inclusive national identity and the embrace of diversity. Ethnic and Racial Studies 34(12): 2153-2172.

Myrdal, G. 1944 [1996]. An American dilemma: The negro problem and modern democracy. New York: Routledge. 
Nelson, A. 2002. Unequal treatment: Confronting racial and ethnic disparities in health care. Journal of the National Medical Association 94(8): 666.

Newman, L.K., M. Dudley, and Z. Steel. 2008. Asylum, detention, and mental health in Australia. Refugee Survey Quarterly 27(3): 110-127.

Nixon, S.A. 2019. The coin model of privilege and critical allyship: Implications for health. BMC Public Health 19: 1637.

Noah, B.A. 2002. The invisible patient. Review of How political correctness is corrupting medicine by S. Satel. University of Illinois Law Review 2002: 121-148.

Paradies, Y. 2016. Racism and health. In The international encyclopedia of public health, 2nd ed., edited by S.R. Quah, and W.C. Cockerham, 249-259. Oxford: Academic Press.

Paradies, Y., J. Ben, N. Denson, et al. 2015. Racism as a determinant of health: A systematic review and meta-analysis. PLOS One 10(9): e0138511.

Paradies, Y., M. Truong, and N. Priest. 2014. A systematic review of the extent and measurement of healthcare provider racism. Journal of General Internal Medicine 29(2): 364-387.

Peeples, L. 2019. What the data say about police shootings. Nature 573(7772): 24-27.

Post, R. 1991. Racist speech, democracy, and the First Amendment. William and Mary Law Review 32: 267-327.

Powers, M., and R.R. Faden. 2006. Social justice: The moral foundations of public health and health policy. Oxford: Oxford University Press.

Pyle, E.A. 2018. Problematising the wickedness of "disadvantage" in Australian Indigenous affairs policy. Master's thesis, Queensland University of Technology.

Rawls, J. 2001. Justice as fairness: A restatement, edited by E. Kelly. Cambridge, MA: Harvard University Press.

Richardson, L.D., and M. Norris. 2010. Access to health and health care: How race and ethnicity matter. Mount Sinai Journal of Medicine 77(2): 16.

Saunders, P., Y. Naidoo, and M. Griffiths. 2008. Towards new indicators of disadvantage: Deprivation and social exclusion in Australia. Australian Journal of Social Issues 43(2): 175194.

Seet, A.Z. 2019. Serving the White nation: Bringing internalised racism within a sociological understanding. Journal of Sociology. https://doi.org/10.1177/1440783319882087.
Shelby, T. 2014. Racism, moralism and social criticism. Du Bois Review: Social Science Research on Race 11(1): 57-74.

Silove, D., Z. Steel, and R.F. Mollica. 2001. Detention of asylum seekers: Assault on health, human rights, and social development. The Lancet 357(9266): 1436-1437.

Stone, J. 2002. Race and healthcare disparities: Overcoming vulnerability. Theoretical Medicine and Bioethics 23(6): 499518.

Taylor, J. 2004. Refugees and social exclusion: What the literature says. Migration Action 22(2): 16-31.

Thomsen, F.K. 2017. Discrimination. In Oxford research encyclopedia of politics. Oxford University Press.

Venkatesan, M. 2018. Review of The color of money: Black banks and the racial wealth gap by M. Baradaran. Journal of American History 105(3): 646-647.

Washington Post. 2019. Data on police shootings 2015-2019. https:/github.com/washingtonpost/data-police-shootings. Accessed November 28, 2020.

White, M., and M. Gooda. 2017. Royal Commission into the Protection and Detention of Children in the Norther Territory. NT Final Report. Canberra: Commonwealth of Australia.

Willard, M. 1967. History of the White Australia policy to 1920. London: Frank Cass and Co. Ltd.

Williams, D.R., and R. Wyatt. 2015. Racial bias in health care and health: Challenges and opportunities. Journal of the American Medical Association 314(6): 555-556.

Williams, P. 2001. Deaths in custody: 10 years on from the Royal Commission. Trends and Issues in Crime and Criminal Justice, no. 203. Canberra: Australian Institute of Criminology.

Wilson, C.A. 1996. Racism: From slavery to advanced capitalism. Thousand Oaks: Sage Publications.

Wilson, W.J. 2010. Why both social structure and culture matter in a holistic analysis of inner-city poverty. Annals of the American Academy of Political and Social Science 629(1): 200-219.

Wolfe, P. 2006. Settler colonialism and the elimination of the native. Journal of Genocide Research 8(4): 387-409.

Publisher's note Springer Nature remains neutral with regard to jurisdictional claims in published maps and institutional affiliations. 